(E-ISSN : 2615-4978, P-ISSN : 2086-4620)

Vol. IX No 2, Nopember 2018

\title{
Bagaimana Analisis Pendapatan Dan Biaya Relevan Atas Bisnis Online?
}

\author{
Denny Anggriawan, Temy Setiawan \\ Universitas Bunda Mulia \\ denny.anggriawa09@gmail.com
}

\begin{abstract}
ABSTRAK
Perkembangan teknologi dan penggunaan jaringan internet yang semakin pesat di tengah masyarakat saat ini berdampak pada perilaku konsumen. Bisnis yang dahulu dilakukan secara konvensional atau offline kini mulai beralih ke bisnis online, yang sangat memudahkan konsumen untuk dapat melakukan transaksi bisnis tanpa ada batasan ruang dan waktu. Penelitian ini bertujuan untuk mengetahui peningkatan laba usaha dengan peralihan offline ke online dengan analisis pendapatan dan biaya relevan. Penelitian ini merupakan penelitian kualitatif deskriptif. Subjek penelitian adalah Toko Hproject. Data yang digunakan adalah data primer dan data sekunder. Teknik pengumpulan data dengan observasi toko offline dan toko online, wawancara dengan pemilik dan karyawan serta dokumentasi atas catatan laporan pembukuan. Berdasarkan hasil penelitian ditunjukkan bahwa peralihan bisnis offline ke online dapat meningkatkan laba usaha berdasarkan analisis pendapatan dan biaya relevan untuk pengambilan keputusan taktis. Kontribusi penelitian ini adalah dapat menujukan bahwa salah satu teknik dalam meningkatkan laba adalah dengan memanfaatkan teknologi dan jaringan dalam berbisnis. Selain itu, penelitian ini dapat memberikan pertimbangan teknik analisis keuangan sebelum pengambilan keputusan taktis pada teknik bisnis.
\end{abstract}

Kata Kunci: offline, online, keputusan taktis

\begin{abstract}
The development of technology and the increasing use of Internet network in the society today has an impact on consumer behavior. Businesses that used to be conventional or offline are now turning to online business, which makes it easier for consumers to be able to conduct business transactions without any limitations of space and time. This study aims to determine the increase in operating income with offline switch to online with the analysis of revenue and relevant costs. This research is descriptive qualitative research. The subject of the research is the Hproject Store. The data used are primary data and secondary data. Data collection techniques with offline store observations and online stores, interviews with owners and employees and documentation of the accounting records. Based on the results of research indicated that switching offline business to online can increase operating profit based on revenue analysis and cost relevant for tactical decision making. The contribution of this research is able to indicate that one of technique in increasing profit is by utilizing technology and network in doing business. In addition, this study can provide consideration of financial analysis techniques before tactical decision making on business techniques.
\end{abstract}

Keywords: offline, online, tactical decision

\section{PENDAHULUAN}

Saat ini perkembangan bisnis sudah mulai bergeser dari bisnis offline menjadi bisnis online (Utomo, 2013; Dumais, Tumbuan, Tumiwa, 2017). Beberapa fakta menunjukkan keberadaan bisnis offline sudah mulai memperlihatkan penurunan yang cukup drastis, antara lain: banyaknya perusahaan ritel di Indonesia yang menutup sebagian toko atau bahkan sampai gulung tikar salah satunya seperti PT Matahari Department Store Tbk yang memutuskan untuk menutup dua gerai miliknya yang berada di Pasaraya Manggarai dan Pasaraya blok M dikarenakan kedua gerai tersebut pemasukannya tidak sesuai dengan yang diharapkan lantaran pengunjung di kedua cabang tersebut terbilang sepi. Ada juga PT Mitra Adiperkasa Tbk yang menutup seluruh gerai Lotus yang tersebar di 5 lokasi pada Oktober 2017 dan PT Matahari Putra Prima Tbk yang dikenal dengan brand Hypermart juga mencatatkan rugi sebesar Rp402,98 miliar per September 2017 (https://finance.detik.com).

Perkembangan dunia teknologi dan jaringan internet yang semakin maju, berdampak pada teknik konsumsi masyarakat, sehingga memunculkan 
saluran belanja baru yaitu secara online (Utomo,2013). Dalam beberapa tahun belakangan, bisnis online di Indonesia menunjukkan pertumbuhannya, banyak perusahaan maupun bisnis usaha kecil dan menengah mulai menjalani bisnis online. Bisnis online memudahkan konsumen atau pelanggan untuk melakukan transaksi bisnis tanpa batasan ruang dan waktu serta menguntungkan bagi produsen dalam menghemat biaya dan memperluas jaringan pemasaran (Kosasi, 2015). Wiyani dan Prabowo (2013) mengatakan jika bisnis offline memiliki wilayah pemasaran yang terbatas maka diperlukan untuk melakukan bisnis secara online.

Selain kemudahan-kemudahan yang ditawarkan oleh bisnis online, terdapat faktor lain juga yang mempengaruhi pergeseran minat beli kosumen dari offline ke online yaitu perbedaan yang signifikan antara toko online dan offline yang diukur dari perbedaan harga (Dumais, Tumbuan, Tumiwa, 2017; Bagla, 2017; Sunil, 2015)

Adanya keputusan taktis atas peralihan bisnis offline ke online selain dari pertimbangan strategi pemasaran yang mengikuti teknik konsumsi masyarakat dalam berbelanja, perlu juga dilakukan analisis secara keuangan (Mandagi, Saerang, dan Pusung, 2014; Tumilantouw, Morasa, Kalangi, 2014). Penelitian ini penting dalam memberikan gambaran analisis pendapatan dan biaya relevan dari peralihan teknik bisnis tersebut sehingga perusahaan tidak hanya mempertimbangkan aspek pemasaran namun juga secara pertimbangan aspek keuangan. Penelitian ini diharapkan memberikan kontribusi bagi akademis dalam memanfaatkan ilmu akuntansi manajemen dalam pengambilan keputusan bisnis dan kontribusi praktik bagi usaha dalam memperhitungkan pendapatan dan biaya relevan dampaknya pada peningkatan laba sebelum melakukan pengambilan keputusan taktis.

\section{TINJAUAN PUSTAKA}

\section{Pendapatan Relevan}

Pendapatan relevan adalah pendapatan masa depan yang diharapkan berbeda diantara alternatifalternatif tindakan yang sedang dipertimbangkan (Horngren dan Foster, 2008; Krismiaji dan Aryani, 2011; Horngren, Datar, Rajan, 2015). Pada penelitian ini pendapatan relevan akan meninjau hasil penjualan offline dengan penjualan online toko HProject.

\section{Biaya Relevan}

Purwaji, et al (2016) menjelaskan biaya adalah pengorbanan sumber daya yang diukur dalam satuan uang, yang mana hal tersebut telah terjadi atau kemungkinan akan terjadi dalam upaya perusahaan untuk memperoleh barang atau jasa. Tidak jauh berbeda dengan Simamora (2012) yang menjelaskan bahwa biaya adalah kas atau nilai setara kas yang dikorbankan untuk barang atau jasa yang diharapkan memberi manfaat pada saat ini atau dimasa mendatang bagi organisasi.

Biaya relevan adalah biaya masa depan yang diperkirakan dan yang berbeda diantara alternatif tindakan yang sedang dipertimbangkan oleh seorang manajer (Horngren dan Foster, 2008; Hansen dan Mowen, 2011). Untuk menjadi biaya relevan, suatu biaya tidak hanya merupakan biaya masa depan, tetapi juga harus berbeda dari satu alternatif dengan alternatif lainnya. Jika biaya masa depan terdapat pada lebih dari satu alternatif, maka biaya tersebut tidak memiliki pengaruh terhadap keputusan. Biaya demikian disebut biaya tidak relevan. Biaya relevan yang dianalisis adalah biaya yang dikeluarkan perusahaan pada bisnis offline dibandingkan dengan biaya yang dikeluarkan pada bisnis online.

Informasi pendapatan dan biaya relevan penting di dalam pengambilan keputusan taktis perusahaan karena dapat melihat peningkatan atau penurunan laba atas keputusan yang diambil berdasarkan pertimbangan aspek keuangan. Simamora (2012), menyatakan bahwa yang membuat suatu informasi menjadi relevan dengan persoalan keputusan ada empat pertimbangan penting yaitu: (1). berkaitan dengan masa depan; (2). berbeda di antara beberapa alternatif; (3). kebutuhan akan prediksi; (4). keputusan unik dan repetitif.

\section{METODE PENELITIAN}

Subjek penelitian adalah Hproject sebuah toko fashion Muslim di Pusat Perbelanjaan Season City Trade Mall, J1. Professor Doktor Latumenten, Jembatan Besi, Tambora, Kota Jakarta Barat. Alasan pemilihan HProject sebagai subjek penelitian karena toko ini awalnya menjalankan bisnis offline kemudian beralih ke bisnis online secara bertahap. Penelitian ini diharapkan dapat memberikan kontribusi dalam pertimbangan aspek keuangan untuk keputusan taktis meninggalkan bisnis offline yang selama ini dijalankan ke bisnis online.

Sumber data yang digunakan adalah sumber data primer dan sumber data sekunder. Sumber data primer diperoleh dengan teknik observasi dan wawancara dengan pemilik dan karyawan sedangkan data sekunder diperoleh dari laporan pencatatan harian toko baik offline maupun online, postingan pelanggan di akun lapak online HProject yaitu Tokopedia dan Shopee.

Untuk memenuhi tujuan penelitian, berikut ini adalah alur penelitian yang dilakukan: 


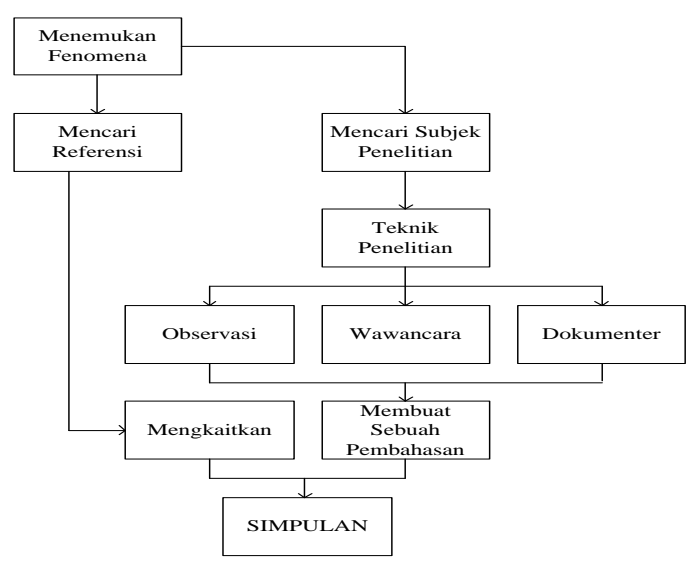

Gambar 1. Alur Penelitian

\section{HASIL PENELITIAN DAN PEMBAHASAN}

Tabel 1 Pendapatan Relevan Tahunan (Rp 000)

\begin{tabular}{lccc}
\hline & $\begin{array}{c}\text { Pendapatan } \\
\text { Offline }\end{array}$ & $\begin{array}{c}\text { Pendapatan } \\
\text { Online }\end{array}$ & Selisih \\
$\begin{array}{l}\text { Jumlah } \\
\text { pendapatan }\end{array}$ & 399.432 & 761.766 & 362.334 \\
\hline
\end{tabular}

Sumber: Olahan peneliti dari hasil dokumentasi catatan penjualan toko secara offline dan rekapan penjualan online di Tokopedia dan Shopee

Tampak dalam tabel 1, penjualan offline sebesar Rp. 399.432.000 dan penjualan online sebesar Rp. 761.766.000 sehingga terjadi selisih positif (favorable) sebesar Rp. 362.334.000. Angka ini merupakan pendapatan relevan antara bisnis offline dan online. Oleh karena itu apabila toko HProject mengganti teknik bisnis offline ke online akan lebih menguntungkan dari pertimbangan aspek keuangan.

Tabel 2. Biaya Relevan Tahunan

\begin{tabular}{|c|c|c|c|}
\hline Biaya & $\begin{array}{c}\text { Biaya } \\
\text { offline }\end{array}$ & Biaya online & Selisih \\
\hline Internet & - & 3.600 .000 & $(3.600 .000)$ \\
\hline Sewa model & - & 1.000 .000 & $(1.000 .000)$ \\
\hline Gaji & 46.800 .000 & 82.800 .000 & $(36.000 .000)$ \\
\hline Diskon & - & 12.000 .000 & $(12.000 .000)$ \\
\hline Packaging & - & 28.200 .000 & $(28.200 .000)$ \\
\hline Endorsement & - & 950.000 & $950.000)$ \\
\hline $\begin{array}{l}\text { Ongkos kirim } \\
\text { retur barang }\end{array}$ & - & 150,000 & $150,000)$ \\
\hline $\begin{array}{l}\text { Biaya sewa } \\
\text { toko }\end{array}$ & $14,830,400$ & - & $14,830,400$ \\
\hline Biaya listrik & $1,800,000$ & - & $1,800,000$ \\
\hline $\begin{array}{l}\text { Biaya } \\
\text { tunjangan } \\
\text { karyawan }\end{array}$ & $7,000,000$ & - & $7,000,000$ \\
\hline $\begin{array}{l}\text { Biaya } \\
\text { depresiasi } \\
\text { prasarana } \\
\text { toko }\end{array}$ & $1,500,000$ & - & $1,500,000$ \\
\hline TOTAL & $71,930,400$ & $128,700,000$ & $(56,769,600)$ \\
\hline
\end{tabular}

Sumber: Olahan peneliti dari hasil dokumentasi catatan penjualan toko secara offline dan rekapan penjualan online di Tokopedia dan Shopee.
Tampak dalam tabel 2, biaya-biaya yang relevan pada bisnis offline maupun online antara lain biaya internet, biaya promosi, biaya diskon, biaya packaging, biaya endorsement, biaya ongkos kirim retur barang, biaya sewa toko, biaya listrik, biaya tunjangan karyawan, biaya depresiasi prasarana toko dan biaya gaji karyawan.

Meskipun baik pada bisnis online maupun offline sama-sama terdapat biaya untuk gaji karyawan, namun terdapat perbedaan total biaya gaji yang dikeluarkan antara bisnis offline dan online. Karyawan untuk offline terkait dengan menjaga toko namun pada bisnis online untuk menerima pesanan sebagai admin, packing dan pengiriman.

Pengeluaran yang utama pada bisnis online adalah kuota internet. Walaupun relatif tidak besar, namun pengeluaran kuota harus dipertimbangkan agar penjualan maksimal. Menurut hasil wawancara dengan pemilik, ia mengatakan:

"Menurut saya biaya kuota itu pasti, biaya internet itu kan termasuk misalkan untuk uploadupload foto, biaya internet itu untuk bisnis online paling pertama. Biaya kuota sebulan itu bisa Rp 300.000."

Biaya lain yang sangat penting dalam bisnis online dan cukup besar jumlahnya yaitu biaya endorsement, seperti yang dikatakan oleh narasumber.

"Biaya promosi yang paling besar itu biaya endorsement, kalau Hproject mau endorse selebgram, kita cari terus kita pilih siapa selebgramnya, itu mahal-mahal fee-nya. Saya cuman sekali doang sih endorse waktu itu fee nya sekitar Rp 950.000 tapi tidak berkala tiap bulan"

Berdasarkan tabel 1 dan tabel 2 yang telah disajikan di atas, maka dapat diketahui besaran peningkatan laba yang dihasilkan pada peralihan bisnis offline ke online, seperti yang disajikan pada tabel 3 di bawah ini.

Tabel 3 Laba Tahunan (Rp 000)

\begin{tabular}{llcrc}
\hline \multicolumn{1}{c}{ Keterangan } & $\begin{array}{l}\text { Bisnis } \\
\text { online }\end{array}$ & \multicolumn{1}{c}{$\begin{array}{c}\text { Bisnis } \\
\text { offline }\end{array}$} & \multicolumn{1}{c}{$\begin{array}{c}\text { Incre- } \\
\text { mental }\end{array}$} & \\
Pendapatan & 761.766 & 399.43 & 362.334 & F \\
Biaya & 128.700 & 71.930 & 56.770 & UF \\
Profit & 633.066 & 327.502 & 305.564 & F
\end{tabular}

Sumber: Olahan peneliti dari hasil dokumentasi catatan penjualan toko secara offline dan rekapan penjualan online di Tokopedia dan Shopee 
Perhitungan pada tabel 3 menunjukkan adanya peningkatan profit yang terjadi meskipun secara biaya pada bisnis online lebih besar dibandingkan dengan bisnis offline. Namun dengan tingginya biaya yang dikeluarkan pada bisnis online tersebut dapat meningkatkan pula pendapatan online-nya, sehingga profit yang dihasilkan pada bisnis online meningkat.

\section{KESIMPULAN DAN SARAN}

\section{Kesimpulan}

Analisa pendapatan dan biaya relevan sangat berpengaruh pada pengambilan keputusan. Menurut perhitungan biaya relevan, biaya yang dikeluarkan pada bisnis online lebih besar dibandingkan pada bisnis offline, namun secara pendapatan relevan dan laba yang didapatkan pada bisnis online jauh lebih besar jika dibandingkan dengan bisnis offline. Sehingga dapat disimpulkan bahwa toko Hproject akan mendapatkan keuntungan yang lebih besar jika memilih untuk melakukan bisnis online dibandingkan bisnis offline.

\section{Saran}

Bagi Hproject, karena menurut penelitian ini bisnis online lebih menguntungkan dari bisnis offline maka akan lebih baik jika Hproject memperluas jangkauan pasarnya dengan berjualan di marketplace yang lainnya yang memiliki reputasi yang baik daripada melakukan ekspansi dengan membuka toko offline baru di tempat lain. Sedangkan bagi penelitian selanjutnya, dapat dilakukan pada perusahaan atau toko yang skalanya lebih besar lagi dan karena keterbatasan penelitian ini hanya mendapatkan laporan penjualan secara bulanan maka diharapkan penelitian selanjutnya dapat memperoleh laporan pendapatan dan biaya perusahaan dalam periode waktu 1 tahun untuk menghindari subjektifitas peneliti yang tinggi dalam menetapkan asumsi.

\section{DAFTAR PUSTAKA}

Bagla, Divya. 2017, Online vs offline shopping. International Journal of Creative and Innovation, Vol. 1, Issue-1, 2017.

Dumais, Lady Priscillia., Tumbuan, Willem J.F.A., Tumiwa, Johan R. 2017, Analisa perbandingan preferensi konsumen antara toko online dan offline (studi kasus pada produk fashion). Jurnal EMBA, Vol.5 No.3, Hal 3282-3291.
Hansen, Don R., dan Mowen, Maryanne M. 2011, Akuntansi Manajerial. Buku Dua. Jakarta : Salemba Empat.

Horngren, Charles. T., Srikant, M. Datar., dan Madhav, V Rajan. 2015, Cost accounting A managerial Emphasis. Harlow : Pearson.

Kosasi, Sandy. 2015, Pembuatan Bisnis Toko Online Sebagai Peluang Usaha Menumbuhkan Pasar Global. Prosiding Seminar Ilmiah Nasional Teknologi Komputer, Vol. 1. Padang, Indonesia: Universitas Putra Indonesia YPTK Padang.

Krismiaji., dan Aryani, Y. Anni. 2011, Akuntansi Manajemen. Edisi Kedua. Yogyakarta : Sekolah Tinggi Ilmu Manajemen YKPN

Mandagi, Wulan Christiana., Saerang, David P.E., dan Pusung, Rudy J. 2014, Analisis Biaya Relevan Dalam Pengambilan Keputusan Menjual Atau Memproses Lebih Lanjut Produk Pada PT. Fortuna Inti Alam. Jurnal EMBA, Vol.2 No.2, Hal 1043-1054, ISSN : 2303-1174.

Purwaji, Agus, Wibowo., dan Sabaruddin, Muslim. 2016, Akuntansi Biaya. Edisi Dua. Jakarta : Salemba Empat.

Sugianto. 2017, Ini Jajaran Ritel yang Tutup Toko di Indonesia available at https: //finance.detik.com/berita-ekonomi-bisnis/d3736180/ini-jajaran-ritel-yang-tutup-toko-diindonesia.

Sunil. (2015). Trend and Practices of Consumers Buying Online and Offline, an Analysis of Factors Influencing Consumer's Buying. IJCOMA, Vol.25 No.4, Pp 442-455.

Tumilantouw, Fredo., Morasa, Jenny., dan Kalangi, Lintje. (2014). Penerapan Biaya Relevan dalam Mengambil Keputusan Menerima atau Menolak Pesanan Khusus pada CV. Piramid. Jurnal EMBA, Vol 2 No.1, pp 677-685, ISSN : 23031174.

Utomo, E. M. (2013). Transaksi E-Commerce Sebagai Potensi Penerimaan Pajak di Indonesia. Jurnal Akuntansi Unesa Vol.2, No.1.

Wiyani, Fitri., dan Prabowo, N. Agung. (2013). Peningkatan Daya Saing "Batik Kahuripan" Melalui Sistem Penjualan Berbasis Ecommerce. Seminar Riset Unggulan Nasional Informatika dan Komputer, Vol.2 No.1, ISSN : 2302-1136. 